\title{
DETERMINANTS OF ROAD TRAFFIC ACCIDENT AMONG COMMERCIAL DRIVERS IN RIVERS STATE
}

\author{
Dr. Samuel G. K. ${ }^{1}$ and Amini Lucy ${ }^{2}$ \\ ${ }^{1}$ Department of Human Kinetics Health and Safety Studies, Ignatius Ajuru University of \\ Education, Port Harcourt \\ Email: gentle.samk@gmail.com \\ ${ }^{2}$ Department of Community Health, College of Health Science and Management Technology, \\ Port Harcourt.
}

Cite this article:

Samuel G. K., Amini L. (2021), Determinants of Road Traffic Accident Among Commercial Drivers in Rivers State. International Journal of Public Health and Pharmacology 1(1), 20-30. DOI: $10.52589 / \mathrm{IJPHP}$ FXQGULH2.

\section{Manuscript History \\ Received: 1 May 2021 \\ Accepted: 20 May 2021 \\ Published: 12 June 2021}

Copyright $\odot 2020$ The Author(s).

This is an Open Access article distributed under the terms of Creative Commons AttributionNonCommercial-NoDerivatives 4.0 International (CC BY-NC-ND 4.0 ), which permits anyone to

share, use, reproduce and redistribute in any medium, provided the original author and source are credited.
ABSTRACT: This study investigated the determinants of road traffic accidents among commercial drivers in Rivers State. Four research questions and hypotheses were formulated to guide the study. The cross-sectional survey design was adopted for the study. The sample size included 400 hundred commercial drivers selected using a purposive and accidental sampling technique. Data was collected using a self-structured questionnaire with a reliability coefficient of 0.72 . Data were analysed using percentages, mean, standard deviation and ANOVA. The result showed that age and drug use were a significant predictor of road traffic accident among commercial drivers in Rivers State $(d f=2$, $F=5.867, p<.05)$ and $(d f=2, F=8.429, p<.05)$. The findings also showed that level of education and years of work experience was not a significant predictor of road traffic accident among commercial drivers in Rivers State $(d f=3, F=1.534, p>.05)$ and $(d f=2, F=0.449, p>.05)$. Based on the findings, it was concluded that drivers' age and drug use significantly predict of road traffic accident whereas drivers' level of education and years of work experience does not a significantly predict of road traffic accident among commercial drivers in Rivers State. It was recommended among others that there should be total enforcement of traffic rules and regulation to correct erring drivers and the Government and affected institutions should take the issue of road construction and maintenance more seriously.

KEYWORDS: Road Traffic Accident, Commercial Drivers, Road Construction, Rivers State, Nigeria 


\section{INTRODUCTION}

Every occupation has its hazards, some are more hazardous than others. Driving is one of the most hazardous jobs. Adherence to safety practice has been a major problem in the global community, especially in industrialisation which is prevalent in developing nations, Nigeria inclusive. Occupational health and safety practices involve different aspects of workers' health, including the physical, mental and social wellbeing of workers in various building construction companies. Occupational health and safety practices deal with the expectation, acknowledgement, assessment and control of hazards emerging in or from the building construction work environment that could impede the safety of commercial drivers (Alli, 2008). Occupational health and safety practices are focused on ensuring the physical, mental and social wellbeing of workers of all categories; this is achieved by controlling hazards, conditions and occurrences which might be hazardous to drivers physical, mental or social wellbeing (Ahmad, Sattar \& Nawaz, 2016). Therefore, occupational health and safety is the process responsible for the development, promotion, and maintenance of the driving environment; it involves policies and programs which not only enhance the mental, physical, and emotional wellness of not just the drivers but also aims to keep the road relatively free from hazards which could bring about injury to the drivers.

Agbonkhese, Yisa, Agbonkhese, Akanbi, Aka, and Mondigha (2013) has it that among 193 countries ranked in motor road accidents, Nigeria ranked the second highest in the rate of road accidents. Conservative data available suggests that Nigeria is a country with an increasing road accidents problem and has been rated as the worst in the world (Asogwa, 1992 in Emelike, Mbanaso, Akunneh-Wariso, Enejoh, Adiele, \& Olo, 2019). Road motor accident is a major contributor to mortality and morbidity in Nigeria (Salako, Adegoke, \& Akanmu, 2014). In an international comparison of road traffic accidents, Nigeria has the worst mortality and morbidity rates among industrialized nations and developing countries from Africa (Asogwa, 1978 cited in Emelike, et al, 2019).

Indeed, news of road traffic accidents in Nigeria no longer stirs any surprise. What may be shocking, however, is the magnitude of the fatality. Most of the fatal accidents are mainly among commercial drivers. Personal observation shows that the high-level road crashes among commercial drivers is as a result of reckless overtaking, non-compliance to the speed limit, nonuse of seat belts, alcohol use among commercial driver are the contributing factors to the high level of road crashes. Emelike, Mbanaso, Wariso, Enejoh, Adiele and Olo (2019) report that private drivers demonstrate a high level of safety practice than commercial drivers. This may also be true among drivers in Rivers State. Equally, a lot of funds are wasted yearly to reduce the trends of road accident on Nigerian roads and highways. For instance, Idoko (2010) submits that Nigeria loses three billion naira every year to road crashes and that road crashes cost Nigeria 13 per cent of her Gross National Product (GNP). This loss undoubtedly inhibits economic and social development.

Older drivers may likely consider safety practices on daily basis compared to younger ones who may be loosed at work. Studies of Kiani and Khodabakhsh (2014) indicate that 34 years of age (mean age) had an increased level of safety practices. The younger workers are usually lethargic to use safety materials at the workplace thereby placed themselves at the risk of accidents. However, safety practices alone do show improve site safety in the construction company. Due to the amateur level of safety practices, the role of management should be interpreted to both the younger and older site workers that wearing at least minimum protective gear is the criteria 
to resume work daily. In a study by Tezera, Chercos and Dessie (2017), safety practice among workers is high among ages 28 years and above as compared with those that age below 28 . On the contrary, Tezera et al (2017) reported that workers age 14-29 years were 7.2times more likely to have good safety practices than older ones. That is, younger ones may quickly respond to safety practices sometimes to show themselves that they are working in a construction company. Therefore, there is variability in safety practices by age of workers concerning the workplace. Moreover, younger workers may show improved motivation and adherence to safety practices because they are at high risk of acquiring injuries at the workplaces. As the construction workers grow older, the behaviour of workers towards safety improved (Azadel, Mohammed, 2009; Nasah, Tavakoli, Ghofrani Pour, Fazemnejad \& Khavarin, 2009; Ibrahim, Al-Hallaq, \& Enshassi, 2012).

The Educational status of the motorist is also an influencing factor towards the knowledge and practice of seatbelt use in Port Harcourt metropolis, Rivers State. This means that the educational level of the drivers increases the seatbelt rate usage. Kulanthanyan, Teik and Umar (2004) has it that the educational level is an influencing factor in determining seatbelt use among motorist, They observed that due to the educational level of the motorists the seatbelt compliance is increased, based on this factor it is observed that most of the motorist are educated people, they have passed through the four walls of an institution, be it secondary, university or driving schools as the case may be, so they are aware and have the knowledge of safety on the road. Futhermore, Chika and Oladimej (2011) observed that many motorists had a positive attitude to use their seatbelt, $95.5 \%$ disagreed with the idea that seatbelt causes an accident, while $80.5 \%$ also disagreed with the belief that seatbelt usage was for an educated motorist.

Years of experience by the motorists implies that the number of years one has driven a vehicle can either prevent the seatbelt usage or encourage the seatbelt usage among motorist in Port Harcourt metropolis, Rivers State. Some motorists have been driving for 10-20years and so the seatbelt use compliance is very low because they feel that the year of experience of a motorist should not determine the usage of a seatbelt, seatbelts should be used properly despite one's year of experience in driving because when an accident occurs or a sudden break is held or even a collision, there is usually injury sustenance and sometimes death which has no respect for years of experience (Ped, 2004). The working experience of workers is a major characteristic that may predict safety practices in road construction. A certain proportion of road construction workers may have less than five (5) works. Experiences would likely fail to maintain good safety practices. Studies of Kolo (2015) revealed that only (23.0\%) of construction workers had 0-5 years whereas over $30.5 \%$ are with 10-16 years of work experiences. The number of years spent in the construction of road determined the number of accidents and injuries they experience. The 10 years' experience, the high rate of safety practice as compared with that of baby experience (Kolo, 2015). The working experience goes a long way to double the level of awareness of safety practices. Similar studies of Ling, Ofori, and Teo (2010) revealed safety participation is higher but site safety practices may decrease, that work experience of workers determine the site safety level in a construction company. The more years a worker spends at the construction site, the increase in the adherence to safety practices. This study, therefore, aimed at assessing determinants of road traffic accident among drivers in Rivers State

\section{Statement of the Problem}

Many occupations within the transport sector have long been linked to a multitude of adverse health outcomes. Taxi, bus, and truck drivers, train conductors, and trolley and cable-car 
operators, among other professional drivers, have experienced musculoskeletal, psychophysiological, gastrointestinal, cardiovascular, and other morbidities (Federal Motor Carrier Safety Administration, FMCSA, 2005). Such health ramifications, which have been predominantly attributed to workplace conditions, have negatively influenced the quality of life of many of these workers (Apostolopoulos, Sönmez, Shattell, \& Belzer, 2010). Occupational hazards among drivers are a routine occurrence on roads throughout the world. Thousands of drivers and passengers lose their lives on the roads every day. Many millions more are left with disabilities or emotional scars that they will carry for the rest of their lives while others are left helpless and hopeless as a result of losing a breadwinner to these hazards.

Several factors increase the likelihood of road traffic injuries occurring, not only among young people but also in the general population. These include speed, lack of seat-belt and child restraint use, drinking and driving, and lack of conspicuity. Interventions to address these specific risk factors have been promoted through the World report on road traffic injury prevention. Strategies to protect children in traffic can include modifications to the environment and vehicles and changes in behaviour. Reckless driving, lack of concern for road signs by commercial motorists and disregard of motorcyclists by pedestrians are common occurrences within the state. These predispose the motorists, passengers and pedestrians to hazards such as bruises, lacerations, dislocations and even fractures in a severe situation. It is based on the aforementioned that this study was conducted to assess the occupational health hazards among commercial motorists in River State.

\section{Aim of the Study}

This study aims to investigate determinants of road traffic accident among commercial drivers in Rivers State.

\section{Research Questions}

The following questions were formulated to guide this study;

1. How is age a predictor of road traffic accident among commercial drivers in Rivers State?

2. How is the level of education is a predictor of road traffic accident among commercial drivers in Rivers State?

3. How is years' work experience a predictor of road traffic accident among commercial drivers in Rivers State?

4. How is drug use is a predictor of road traffic accident among commercial drivers in Rivers State?

\section{Hypotheses}

The following null hypotheses were tested at a 0.5 level of significance.

1. Age is not a significant predictor of road traffic accident among commercial drivers in Rivers State. 
2. The level of education is not a significant predictor of road traffic accident among commercial drivers in Rivers State.

3. Years' work of experience is not a significant predictor of road traffic accident among commercial drivers in Rivers State.

4. Drug use is not a significant predictor of road traffic accident among commercial drivers in Rivers State.

Research Design: This study adopted a cross-sectional survey design. This design will attend to describe, explain and predicts the events or phenomenon at a fixed point in time.

The population of the Study: The population of this study comprised all commercial drivers in Rivers State.

Sample and Sampling Techniques: The sample size for the study consisted of 400 commercial drivers. The sample size for the study was determined using the Yaro Yamane method for a finite population. A multi-stage sampling procedure was used for the study.

The instrument for Data Collection: The instrument used for data collection was a selfstructured questionnaire tagged "determinants of road traffic accident among commercial drivers". The questionnaire was made up of two sections A and B. Section A is designed to elicit personal data, Section B consisted of questions on variables under study.

Validity of the Instrument: To ensure the validity of the instrument, the instrument was reviewed by the research supervisor, and three other experts from the Department of Human Kinetics, Health and Safety Education. Suggestions made were used to make modifications. This move is targeted to ensure that the instrument would satisfy its purpose by measuring what is it supposed to measure.

Reliability of Instrument: A test-retest method was employed using a scout of the instrument (20 copies) administered to commercial drivers in Ahoada and after two the same copies were re-administered. The reliability coefficient value was obtained using Cronbach alpha. The instrument attained a reliability coefficient of 0.72 .

Procedure for Data Analysis: The result were obtained using descriptive and inferential statistical tools include simple percentage, mean and ANOVA. 


\section{RESULTS}

$\mathbf{H}_{01}$ : Age is not a significant predictor of road traffic accident among commercial drivers in Rivers State?

Table 6: Summary of one way ANOVA on how age is a predictor of road traffic accident among commercial drivers in Rivers State

\begin{tabular}{lccccc}
\hline \multicolumn{5}{c}{ ANOVA } & \\
\hline Accident & $\begin{array}{c}\text { Sum of } \\
\text { Squares }\end{array}$ & df & $\begin{array}{c}\text { Mean } \\
\text { Square }\end{array}$ & F & p-value \\
\hline $\begin{array}{l}\text { Between } \\
\text { Groups }\end{array}$ & 3.575 & 2 & 1.788 & 5.867 & 0.003 \\
Within Groups & & & & & \\
& 116.699 & 383 & 0.305 & & \\
Total & 120.274 & 385 & & & \\
\hline
\end{tabular}

Table 6 shows the summary of one way ANOVA on how age is a predictor of road traffic accident among commercial drivers in Rivers State. The result showed that Age is a significant predictor of road traffic accident among commercial drivers in Rivers State $(\mathrm{df}=2, \mathrm{~F}=5.867$, $\mathrm{p}<.05)$. The null hypothesis was rejected at 0.05 alpha level.

Ho2: Level of education is not a significant predictor of road traffic accident among commercial drivers in Rivers State?

Table 7: Summary of one way ANOVA on how the level of education is a predictor of road traffic accident among commercial drivers in Rivers State

\section{ANOVA}

\begin{tabular}{lccccc}
\hline Accident & Sum of Squares & df & Mean Square & F & p-value \\
\hline $\begin{array}{l}\text { Between } \\
\text { Groups }\end{array}$ & 1.432 & 3 & 0.477 & 1.534 & 0.205 \\
Within Groups & 118.842 & 382 & 0.311 & & \\
Total & 120.274 & 385 & & & \\
& & & & & \\
\hline
\end{tabular}

Table 7 shows the summary of one way ANOVA on how the level of education is a predictor of road traffic accident among commercial drivers in Rivers State. The result showed that the level of education is not a significant predictor of road traffic accident among commercial drivers in Rivers State $(\mathrm{df}=3, \mathrm{~F}=1.534, \mathrm{p}>.05)$. The null hypothesis was retained at 0.05 alpha level.

H03: Years of work experience is not a significant predictor of road traffic accident among commercial drivers in Rivers State? 
Table 8: Summary of one way ANOVA on how years of work experience is a predictor of road traffic accident among commercial drivers in Rivers State

\section{ANOVA}

\begin{tabular}{lccccc} 
Accident & Sum of Squares & df & Mean Square & F & p-value \\
\hline Between Groups & 0.281 & 2 & 0.141 & 0.449 & 0.639 \\
Within Groups & 119.993 & 383 & 0.313 & & \\
Total & 120.274 & 385 & & & \\
\hline
\end{tabular}

Table 8 shows the summary of one way ANOVA on how years of work experience is a predictor of road traffic accident among commercial drivers in Rivers State. The result showed that drivers' years of work experience is not a significant predictor of road traffic accident among commercial drivers in Rivers State $(\mathrm{df}=2, \mathrm{~F}=0.449, \mathrm{p}>.05)$. The null hypothesis was retained at 0.05 alpha level.

$\mathbf{H}_{\mathbf{0 4}}$ : Drug use is not a significant predictor of road traffic accident among commercial drivers in Rivers State?

Table 9: Summary of one way ANOVA on how drug use is a predictor of road traffic accident among commercial drivers in Rivers State

\section{ANOVA}

\begin{tabular}{lccccc}
\hline Accident & $\begin{array}{c}\text { Sum of } \\
\text { Squares }\end{array}$ & df & $\begin{array}{c}\text { Mean } \\
\text { Square }\end{array}$ & F & p-value \\
\hline Between & & & & & \\
Groups & 5.071 & 2 & 2.535 & 8.429 & 0.000 \\
Within Groups & 115.203 & 383 & 0.301 & & \\
Total & 120.274 & 385 & & & \\
& & & & & \\
\hline
\end{tabular}

Table 9 shows the summary of one way ANOVA on how drug use is a predictor of road traffic accident among commercial drivers in Rivers State. The table shows that drug use is a significant predictor of road traffic accident among commercial drivers in Rivers State $(\mathrm{df}=2$, $\mathrm{F}=8.429, \mathrm{p}<.05)$. The null hypothesis was rejected at 0.05 alpha level. 


\section{DISCUSSION OF FINDINGS}

\section{Age and Road Traffic Accident among Commercial Drivers}

The result showed that age is a significant predictor of road traffic accident among commercial drivers in Rivers State $(\mathrm{df}=2, \mathrm{~F}=5.867, \mathrm{p}<.05)$. This means that the younger age of driver causes accident among commercial drivers in Rivers State. This may be attributed to the fact that younger drivers are always at a high speed when compared to older ones. The findings align with that of Adejugbagbe, et al (2015) which recorded that age ( $\mathrm{OR}=2.2,95 \% \mathrm{CI}=1.4-3.5$ ) significantly predict road traffic accident among commercial drivers. In the same vein Zeleke (2017) also reported that the age of a driver significantly predicts road traffic accident among commercial drivers. Similarly, Silva, et al (2012) reported that age odds ratio $[\mathrm{OR}]=1.77$ ) was independently associated with reports of accidents. Also in line with the results is a study by Shaheed (2010) which reported that age contributes to the occurrence of accidents. In the same vein the study results agree with the results of Tumwesigye, et al (2016); Lerner, et al (2011); Mohammadi, et al (2015) which reported that age determines the occurrence of road traffic accidents. However, in contrast with the findings in studies of Ogunmodede et al (2012) where it was recorded that age does not significantly influence the causes of road accidents among commercial drivers in Nigeria. This might be attributed to the fact that old age contributes to less road traffic accident especially amongst drivers that require the use of the mind. However, job experience and training including proper job placement can play an important role.

\section{Level of Education and Road Traffic Accident among Commercial Drivers}

The result showed that level of education is not a significant predictor of road traffic accident among commercial drivers in Rivers State $(\mathrm{df}=3, \mathrm{~F}=1.534, \mathrm{p}>.05)$. This implies that the level of education does not predict traffic accidents among commercial drivers in Rivers State. The findings are in line with that of Shaheed (2010) which disclosed that educational level does not significantly predict road traffic accident. The findings also correspond with Ogunmodede, et al (2012) and Yunusa, et al (2014) where it was recorded that educational level does not significantly influence the causes of road accidents among commercial drivers in Nigeria. However, the findings are in contrast with that of Yongchaitrakul et al (2013) which report that a low educational level is associated with road traffic accidents. Also at variance with the findings is studied by Adejugbagbe, et al (2015) where it was recorded that education $(\mathrm{OR}=2.7$, 95\% CI=1.5-4.6) predicts road traffic accident among commercial drivers. Similar, Oliveira et al (2012) report accidents among commercial drivers of secondary and higher educational status. Also in disagreement with the findings is the study of Zeleke (2017) which recorded that level of education significantly predict accident occurrence. The difference in studies may be due to the level of unemployment rate in developing countries and the geographical location of the study.

\section{Years of work experience and Road Traffic Accident among Commercial Drivers}

The result showed that drivers' years of work experience is not a significant predictor of road traffic accident among commercial drivers in Rivers State ( $\mathrm{df}=2, \mathrm{~F}=0.449, \mathrm{p}>.05)$. This means that years of driving experience does not predict road traffic accident. This may be attributed to the fact that an accident can occur at any instance be it someone that has been driving for a long time or not, an accident is not planned. The findings are in line with that of Nyachieo (2015) does not significantly predict road traffic accident among commercial drivers. The 
finding of Jazari et al (2018) agrees with the finding of the present study as it discovered a nonsignificant difference between years of working experience and road traffic accident. However, at variance with the results is the study of Zeleke (2017) which reported that a driver's driving experience was a significant predictor of road traffic accident among drivers. Similarly, Silva, et al (2012) reported that years of working experience contribute to road traffic accidents. Also, studies by Tumwesigye, et al (2016) also recorded that years of experience determine road traffic accidents among commercial drivers. The finding of Jazari et al (2018) and Berhe et al (2015) also disagree with the finding of the present study as they reported a significant difference between years of work experience and road traffic accident. The difference in study results may be attributed to the study location and respondents.

\section{Drug use and Road Traffic Accident among Commercial Drivers}

The results showed that drug use is a significant predictor of road traffic accident among commercial drivers in Rivers State $(\mathrm{df}=2, \mathrm{~F}=8.429, \mathrm{p}<.05)$. This implies that the use of drugs such as alcohol, marijuana, cocaine, tramadol among others significantly contribute to road traffic accidents among commercial drivers in Rivers State. This can be attributed to the fact that drug alters the perception of an individual and reality. The findings are in keeping with that of Asefa, et al (2015) which reported that the history of alcohol use (AOR $=1.51,1.00$ 2.28) was also associated with higher odds of road traffic crash involvement. Also, in consonance with the findings in the study by Bekibele, et al (2007) which reported that the prevalence of RTA was lower amongst drivers who did not take alcohol, cola nut and other CNS stimulants while driving (OR 0.9, 95\% CI=0.3-2.3, P >0.05). Similarly, Adejugbagbe, et al (2015) recorded that alcohol use $(\mathrm{OR}=1.8,95 \% \mathrm{CI}=1.2-3.0)$ significantly predict road traffic accident among commercial drivers. Ogunmoded, et al (2012) also recorded that alcoholic intake predisposes drivers to accidents. Johnson (2012) also reported a significant influence of drug and accident prevalence among drivers. The similarity in studies may be attributed to the fact that drug use exhibits a similar effect among users globally.

\section{CONCLUSIONS}

Conclusively, Drivers' age and drug use significantly predict road traffic accident among commercial drivers in Rivers State $(\mathrm{p}<.05)$. While drivers' level of education and years of work experience do not significantly predict road traffic accident among commercial drivers in Rivers State (p>.05).

\section{RECOMMENDATIONS}

Based on the findings, the following recommendations are made:

1. There should be total enforcement of traffic rules and regulation to correct erring drivers and the Government and affected institutions should take the issue of road construction and maintenance more seriously. 
2. There is a need for road safety education and campaigns, by the FRSC and VIO, directed at vehicle owners and/or drivers especially women. Such road safety education should be focused on safe driving and avoidance of risky behaviours such as the use of mobile phones.

3. There is a need for traffic control and restriction of speed such as T-junctions and U-turns; such traffic controls methods include the use of traffic lights or manning by traffic wardens.

4. To reduce single/runoff vehicle accidents, motorists should be advised to drive within speed limits and at speeds consistent with road and vehicle conditions.

5. The Ministry of transport should make driving schools so that driver's license holders will have full knowledge of traffic rules.

\section{REFERENCE}

Afolabi, J. O. (2014). "Passenger Satisfaction in Public Bus Transport in Nigeria," Unpublished M.Sc Dissertation. OOU Ago-Iwoye.

Badejo, B. A. (2011). "Transportation," Removing the Clogs to Nigeria's Development," Anchorage Press and Publisher, Lagos Nigeria.

Button K. J. \& Hensher, L. (2012). "Handbook of Transport Systems and Traffic Control" Pergamon United Kingdom.

Doherty, S.T., Andrey, J.C. \& MacGregor, C. (2008). The situational risks of young drivers: The influence of passengers, time of day and day of the week on accident rates. Accident Analysis \& Prevention. 30(1): 45-52.

Federal Republic of Nigeria, Federal Road Safety Corps, (2014). 2013 Annual Report. Abuja: Author; 79-90.

Gbadamosi, K. T. (2015). "Spatial Trend and Management of Road Traffic Fatalities in Nigeria," Academic Journal of Interdisciplinary Studies MCSER Publishing, RomeItaly

Jacobs, G., Aeron-Thomas, A. \& Astrop, A. (2000). Estimating global road fatalities. Berkshire: Transport Research Laboratory; 1-26.

Jha N, Srinivasa, D.K., Roy, G. \& Jagdish, S. (2014). Epidemiological Study of Road Traffic Accident Cases: A Study From South India. Indian Journal of Community Medicine. 29(1): 20-24.

Juillard, C., Labinjo, M., Kobusingye, O.C. \& Hyder, A.A. (2009). The burden of road traffic injuries in Nigeria: results of a population-based survey. Injury Prevention, 15:157-162.

Mumby D. L. (2008). “Transport," Selected Readings. Harmondsworth: Penguin.

Odero, V.M., Garner, P. \& Zwi, A. (2009). Road traffic injuries in developing countries: a comprehensive review of epidemiological studies. Tropical Medicine \& International Health. 2009; 2(5): 446 - 460.

Ogunsanya, A. A. (2012). "Maker and Breaker of Cities 59th Inaugural Lecture," University of Ilorin.

Van-Schoor, O., Van-Niekerk, J.L. \& Grobbelaar, B. (2010). Mechanical failures as a contributing cause to motor vehicle accidents - South Africa. Accident Analysis and Prevention. 33: 713-721. 
Violanti, J. M. \& Marshall, J. R. (2011). Cellular phones and traffic accidents: An epidemiological approach. Accident Analysis \& Prevention. 28(2): 265-270.

Vorko-Jović, A., Kern, J. \& Biloglav, Z. (2013). Risk factors in urban road traffic accidents. Journal of Safety Research. 37(1): 93-98.

World Health Organization (2015). Global Status Report on Road Safety, Geneva: Author;175. 